\title{
Library Impact with International Rankings-One Library's Continuous Journey to Figure it Out
}

\author{
Liz Bernal \\ Case Western Reserve University, USA
}

\begin{abstract}
:
Over the past year, a major initiative has occurred at Case Western Reserve University (CWRU) to help determine why the international ranking of the university keeps declining year after year. In the summer of 2017, a task force was formed by the university president and was charged with determining the cause of the decline and learn how to improve the rankings moving forward. The task force determined that all three major rankers (Times Higher Education, QS, and Shanghi (also known as ARWU)), use citation data and academic reputation as components within the scoring, so the library was asked to complete an initial analysis of the bibliometric data to identify issues that may impact the ranking. Thus began the process of data mining inside the two tools that the big three rankers relied on for their citation data: Web of Science (WoS), from Clarivate Analytics, and Scopus, from Elsevier. After completing a deep dive analysis to identify errors, the assessment librarian made changes necessary to clean up the records. By sheer tenacity, the library became one of the leading departments on this initiative, using data mining tools to correct many mistakes within the abstract/citation databases, clearly communicating with vendors and international ranking organizations on issues involving the bibliometrics, putting into place procedures and processes to improve accuracy of bibliometric data for the university, and working with faculty to try and improve their international reputations.
\end{abstract}

\section{INTRODUCTION:}

Case Western Reserve University is a medium-sized high impact research university located in Cleveland, Ohio, with origins dating back to 1826. The university was federated in 1967 in a collaboration between Western Reserve University and the Case School of Applied Science. Currently, CWRU has over 10,000 students and over $50 \%$ are enrolled as professional graduate students, which leads to great possibilities for research. The new Case Western Reserve University (CWRU) "immediately became a leading institution for academics and research," recognized nationally and internationally. Due to this exemplary reputation, it has been essential to assess the direction of the university, through strategic planning and developing initiatives, to remain a leading university across the country and around the world. The university's 2013-2018 strategic plan aimed "to be recognized internationally as an institution that imagines and influences the future," and the strategic plan counted international engagement as one of the core values along with making strides to "deepen and expand the university's international engagement over the next five years." ${ }^{2}$ As part of this pledge, the university opened the Center for International Affairs to ensure that CWRU was moving in an upward direction. Even with these initiatives in place, over the past few years CWRU has been losing ground in their international rankings. If left unchecked, a drop in rankings can directly and indirectly impact the university's partnerships, student and faculty recruitment and retention, research opportunities, as well as funding and overall institutional reputation. Upon seeing the rankings in 2018 from the major ranking agencies, the university realized that steps needed to be taken to reverse the downward trajectory that was occurring. The university librarian and the vice-president of international affairs began working together to move the university forward with a strategic process on improving the rankings. This included determining how the library could help change the trajectory. This paper will introduce readers to the top international ranking agencies that institutions should recognize and the overall process KSL took when introduced to research assessment and define the bibliometric processes and procedures that were developed over the past year while working on this project.

\section{RANKING AGENCY BACKGROUND:}

If you search the internet for "college and university rankings," 3 a list of different ranking agencies appear in the results; however, it is difficult to differentiate and determine which ones are the most important to your 
university. While it is not the best way to learn about rankings, it will direct you to the names of the ranking agencies and the corresponding websites. Fortunately, CWRU hired an international rankings consultant who indicated there are three agencies that most countries and international universities look to for reputation. They are known as the "Big Three": Times Higher Education (THE) World Rankings, QS World Rankings, and Academic Ranking of World Universities (ARWU), also known as Shanghai Rankings. The reason why these are so notable is because they are a few of the longest-running ranking agencies. They are looked to for guidance by universities throughout the world to determine with which school their students, researchers, and educators should engage and collaborate. Or by students, for which schools their government will help fund in aid to allow their attendance. This is a topic that will not be covered in this paper; however, it is important to note certain international countries will not fund students who wish to attend schools that fall below a certain ranking within the list.

Each ranking agency is slightly different and their methodology is not perfect for bibliometric data. Ranking variables differ between each agency: the number of institutions ranked, citation and author impact, total output by the university, subject and performance areas, method of counting, and how data is calculated and normalized are just a few examples. It is important to note, each ranking agency uses a different supplier of the citation data, either Clarivate Analytics or Elsevier. The suppliers review different subject and performance areas and have their own methodology on normalization and results. Many may question why universities or schools examine or believe this information, due to the differences listed above. However, the ranking agencies, especially the ones listed below, still give researchers, collaborators, and prospective students direction in their pursuits.

- Times Higher Education (THE) World Rankings: THE has been ranking institutions and supplying data to prospective students for about 50 years. They currently review more than 1,250 universities as of 2019, and currently have thirteen performance indicators grouped into five major areas: teaching (the learning environment); research (volume, income and reputation); citations (research influence); international outlook (staff, students and research); and industry income (knowledge transfer). ${ }^{4}$ For KSL, the main area of importance is citations, which counts for $30 \%$ of the total indicator score. The citations are supplied by Elsevier and the range is six years of citation count. For 2019, Elsevier examined "67.9 million citations to 14.1 million journal articles, article reviews, conference proceedings, books and book chapters published over five years. The data includes more than 25,000 academic journals indexed by Elsevier's Scopus database and all indexed publications between 2013 and 2017. Citations to these publications made in the six years from 2013 to 2018 are also collected." 5

- QS World Rankings: Currently, QS includes 1,000 universities from 85 countries and is reviewing six metrics: Academic Reputation, Employer Reputation, Faculty/Student Ratio, Citations per faculty, International Faculty Ratio, International Student Ratio. ${ }^{6}$ QS obtains the bibliometric data from Elsevier.

- Academic Ranking of World Universities (ARWU), also known as Shanghai Rankings, was "first published in June 2003 by the Center for World-Class Universities (CWCU)." 7 ARWU has different categories: "six objective indicators to rank world universities, including the number of alumni and staff winning Nobel Prizes and Fields Medals, number of highly cited researchers selected by Clarivate Analytics, number of articles published in journals of Nature and Science, number of articles indexed in Science Citation Index-Expanded and Social Sciences Citation Index, and per capita performance of a university." " ARWU is the only ranker considered one of the "Big Three" that uses Web of Science (WoS) in their analysis. More than 1,200 universities are ranked by ARWU every year and the best 500 are published.

The next few agencies are also ones to watch due to the indicators that are taken into consideration with their use of bibliometric data. These are not as highly cited by countries to make decisions but still used for understanding how institutions are viewed by other countries and institutions around the world. 
- National Taiwan University (NTU) Ranking reviews about 800 universities and uses WoS as the bibliometric source. "Data used to assess the performances of the universities was drawn from ISI's ESI and Web of Science Core Collection (WoS), which includes SCI and SSCI, and Journal Citation Reports (JCR)." 9

- Center for Science and Technology Studies (CWTS) Leiden Ranking is one of the only rankers that is strictly bibliometric in nature and also uses WoS for the base data. "The CWTS Leiden Ranking 2018 includes 938 universities worldwide. These universities have been selected based on their number of WoS indexed publications in the period 2013-2016."10

- US News \& World Report Education Best Global Universities Rankings is made up of 1,250 universities in 75 countries and are ranked based on 13 indicators, which include the following: global research reputation, regional research reputation, publications, books, conferences, normalized citation impact, total citations, number of publications among the 10 percent most cited, percentage of total publications among the 10 percent most cited, international collaboration, percentage of total publications with international collaboration, number of highly cited papers among the top 1 percent most cited in their respective field, and percentage of total publications that are among the top 1 percent most highly cited papers. ${ }^{11}$ US News also uses WoS to make up the bibliometric dataset, but they also use Clarivate Analytic InCites to create the pool of institutions they will review. "To create the pool of 1,372, US News first included the top 250 universities in the results of Clarivate Analytics' global reputation survey, described further below. Next, US News added 1,368 institutions that had met the minimum threshold of 1,500 papers published in the 20122016 time frame. The last step was to remove duplicates and institutions that are not schools to reach the final 2018 ranking pool of 1,372 institutions." 12

\section{PROJECT TIMELINE:}

Starting in fall 2017, the university librarian asked the KSL assessment librarian to identify ways of improving the university's international rankings. The assessment librarian looked into the main ranking agencies and completed a review of the indicators from the big three rankers to see where the library could assist. It was discovered that bibliometric data was included in 15 to $30 \%$ of the overall indicators and it could be said that bibliometrics make up the foundation of most indicators due to academic reputation, faculty output, collaboration, and citation impact. These areas laid the groundwork to begin the project with the top areas of focus on reviewing institution variations followed by reviewing faculty and their affiliations.

KSL had been doing analysis with WoS and InCites since late 2015, using the tool for collection assessment and library peer comparison. This would be the first time these tools were used to assess the university and review the backend data that created the CWRU data set. It was important to learn how the university was represented since the institution had past names. Looking at all institutional variations for CWRU including all professional schools, institutes, research labs, and previous school names were reviewed and accounted for during this project. It becomes a daunting task but determining the steps a librarian would potentially take helps.

\section{Step I: Institutional Name Variation Clean Up also known as so much data}

The first area tackled was institutional name variation and affiliations associated with the university, and to discover if those affiliations were separate entities or university variations. This is important because some institutions must consider if each professional school would or should receive its own affiliation entry in WoS and Scopus and be its own entity. For example, some institutions may want to analyze their professional schools separately to help gauge the different aspects necessary for accreditation, collaboration, or assessment. Note: all work was completed using WoS and their analytic tool InCites for the first few phases of this process because the campus did not have access to Scopus or SciVal at the time. 


\section{Figure 1 WoS Naming Variations}

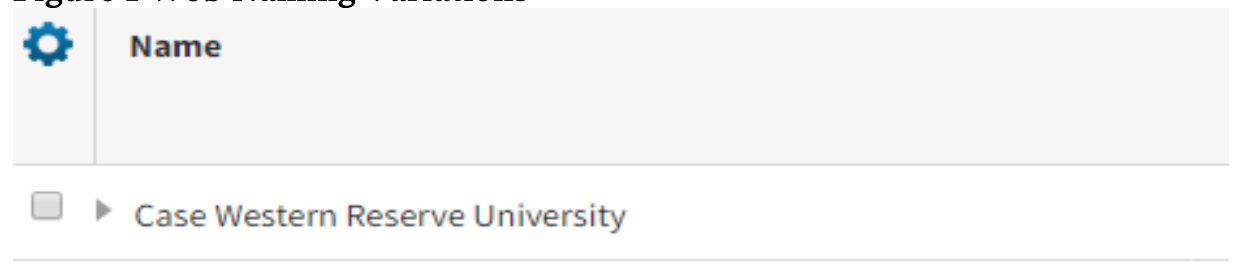

\section{- Case Western Reserve University Hospital}

The path CWRU took was related to how WoS was already set up and only focused on the overarching main affiliation/variation. There is a separate "hospital" variation but, due to the limited information in that profile, the assessment librarian only focused on the main university variation. The librarian did ensure that anything listed under "hospital" was added to the main version already listed in WoS. This meant that no matter how an author documented their affiliation for Case Western Reserve University, WoS would associate the author with CWRU.

Making this decision simplified the process for the librarian as we learned of new variations. Since CWRU is a medium-sized school with only about 10,000 students and 3,000 faculty, the "one campus" approach was the best option. The librarian did recognize there might be questions regarding the "one campus" approach since all departments and schools were now under the general Case Western Reserve University name and, if a department head was searching for faculty in their respective school, they could not do it in one click. It would take additional time but the department head would be able to search for their respective faculty through publication sets pulled from WoS. InCites allows publication datasets to be loaded into the analysis tool which can also be an option in analyzing specific areas of the institution. Plus, this leverages the library's ability to complete research assessment for the school as a whole and better partner with the departments, faculty members, and administrators. If an institution does not want to have the "one campus" approach, then it will be up to that school to request the addition of variations and affiliations as well as maintaining lists of those variations.

Once the basic organization was decided, the librarian was able to move to the next step: determining what institutional variations were in WoS. The librarian accessed the "Organization-Enhanced" dataset in WoS and pulled a list of 215 variations, which the librarian considered to be a good-sized list; it was assumed that this list would not need many more variations. The librarian was very, very mistaken.

The next part of the cleanup process was to contact the three professional library directors who support the health science schools, school of social work, and the school of law, to determine how many variations they were aware of for each of their schools. The assessment librarian provided them the list that was accessed through WoS to help them see a baseline of what was already discovered. The directors provided another 200 variations (the majority were from the health science areas). It was immediately evident that all of the schools indicated their research labs, institutes, use of office numbers, buildings, and different iterations of CWRU, as well as combinations of CWRU with second affiliations, in different ways that were not accounted for in the original dataset. The assessment librarian now had a list of over 400 variations of CWRU and needed to add them to WoS; this became an almost-six-month service request to Clarivate Analytics Support to make changes to the "Organizational-Enhanced" field and have all of the new variations added to the system. These requests were submitted at the time WoS moved from Thomson Reuters to Clarivate Analytics, which caused a massive delay in the completion of the service request. Due to the delay, much of the data generated from WoS was inaccurate and incomplete in order to meet the international ranking agency submissions deadlines.

The next part of the cleanup was the most time-consuming: it involved pulling the top researchers in the university from each school and department and going through the articles that listed CWRU as their affiliation. This was a way to start compiling other random university variations for each of the schools and 
departments. At KSL, the librarian had two student workers to help support this effort and was able to add 100 additional variations.

During this time KSL started a trial of Elsevier's Scopus platform to use in the variation data cleanup as well, and began the same analysis using that tool. It was helpful to see the differences between the two systems and helped support the cleanup effort using both tools.

The assessment librarian performed data cleanup in Scopus and WoS for all the institutional variations and compared the lists being created and was able to make sure the two lists were identical. To date, CWRU has over 650 institutional variations in Scopus and WoS. These lists have been shared with the three major international rankers to ensure when data is pulled into their systems, everything matches to the best of the library's ability.

By using a project management outline in Excel, the library is now on a cycle to ensure all new variations and affiliations are updated accordingly, prior to any submission to international ranking agencies.

\section{Step 2: Author Clean Up Also Known as Author Name Descrambling}

Once the institutional naming variation process was under control, the next focus was on the author naming variations.

First, the librarian contacted the Office of Institutional Research (IR) to learn all of the faculty names. This proved difficult because CWRU has a large cohort of researchers and clinicians based within the hospitals. The librarian determined it would be best to start with the faculty that are $100 \%$ paid by the university. This means these faculty were either board-appointed, tenure-tracked, or located on the main campus and were counted by IR as a full time employee (FTE) in IPEDS. This reduced the list from over 6,000 names to a manageable 1,500+ names. This decision was made to attempt to start small and then expand as the process developed. The smaller list contained faculty that most likely had a primary affiliation with CWRU and not another institution.

Starting with the schools supported by KSL (College of Arts and Science (CAS), School of Engineering (ENG), and the School of Management (WSOM)), the librarian began reviewing two parts of the author's profile in Scopus and WoS: how the university was listed in the indexed item and how the faculty's name was listed. The librarian reviewed each name and any corresponding curriculum vitae found on the CWRU website to make adjustments to the profiles. This was a very time-consuming process with a lot of data to review. In order to reduce the risk of errors, the assessment librarian made the decision to assign one senior student worker to assist with the task of submitting corrections to WoS or Scopus to merge or adjust a faculty member's profile.

For WoS or InCites (where the analyzing was first completed), the only change that was made to a faculty member's profile was if the university was incorrectly attributed. For example, a correction was submitted to a technical support team for an entry that listed CWRU's location as "Cleveland, Sweden". Author errors were also corrected as they were found, ensuring names were accurate. InCites does not allow major changes to author profiles, including combining different name versions like "JR Smith," "John Robert Smith," "J Smith," and so on. This might be frustrating as corrections are being made. However, it also removes incorrect combinations of different names that Scopus has in their system. There is a feature that allows the naming versions to be combined together (called "pinning") to see the aggregate author information in one spot. One thing to note about WoS is that it takes time to receive the corrections with an average of six to ten weeks; however, they appear to be getting faster in their turnaround to process support requests.

On the other hand Scopus can complete an update in as little as two weeks, but the quick turnaround for requests and updates can sometimes cause headaches. In Scopus, anyone can request to make changes to the author profile. This is very convenient when cleaning small errors, such as spelling and merging naming 
differences for authors. Two problems emerge with this open capability to correct errors, though. One is when faculty work and publish for multiple organizations. Technically, the author is connected to each institution and, because profiles can be updated by anyone, users will find that highly-cited faculty with multiple teaching assignments will move from one school to another, even if the faculty member published under one's own institution. The second comes when two faculty members in the same institution have the same name (or appear to have the same name, i.e., "John R Smith" or "John A Smith"). Some profiles will have the initials while others will not, and if they work in the same department, it becomes critical not to merge the two profiles without ensuring the information is accurate. One error KSL discovered consisted of a faculty member being attributed to another's profile and it took weeks to determine what publications belonged to which faculty member before sending the information to Scopus for correction. This is why it is so important to limit how many people work on this in the early stages of the project. It helps reduce errors and allows for the ability to document processes and issues that will ultimately benefit the future stages of the project.

Once the first round of cleanup was completed, the assessment librarian turned to the Research Service Librarians (RSLs) to ask for their support during the second round of cleanup. This allowed for additional help and, due to their connections with the faculty, they would be able to do a more detailed review of faculty profiles.

\section{Step 3: Collaboration Also Known As Asking for Help}

In early 2018, the assessment librarian completed the basic cleanup of 1,500+ faculty names provided by IR for the 2017-18 academic year. Now it was time to ask for help from other staff familiar with faculty to see what additional cleanup efforts were needed.

Discussions began with the Research Services team leader to request that all RSLs review their department lists and work with their individual faculty to determine if the information listed in WoS and Scopus was accurate. During these meetings with their faculty, RSLs would also help create ORCID iDs, if needed.

The team leader whole-heartedly agreed with the process outlined and the project launched by the end of the 2018 spring semester. However, the timing was tricky. Some faculty were leaving on break and all were busy with the end of the semester approaching, RSLs had some time constraints, and other major library initiatives were occurring, but it was decided that, since this would be an ongoing process, it would launch and continue as a summer project. The assessment librarian began working with the RSLs to instruct on the use of WoS/InCites and Scopus/SciVal so they could teach their faculty and assist with improving faculty profiles. It was interesting to learn this exercise also helped the RSLs that have previously published realize that they, too, needed to clean up their profiles and get an ORCID iD to manage their publications and works. They were able to use themselves as examples when speaking with the faculty about the importance of updating their faculty profiles in the two systems.

The number one question faculty asked was, "Why? Why should I do this? This seems like more work," or, "I already put this information on my CV, or in another portal like Google Scholar." Another message we received was, "It's just a way for the university to track what I do and I don't want to do that." These were hurdles the RSLs were equipped to handle through the communication pieces the assessment librarian put together.

Below are a few talking points the assessment librarian provided the RSLs to explain the importance of the project to their faculty, no matter which stage they are in their career and no matter their thoughts on the process.

- This is to ensure you are properly recognized for all of the work that you do instead of someone else that just happens to have your name.

- You will be searchable by others that are doing the same or similar work as you, so it is important to have accurate information in your profile. Someone may be searching in WoS/InCites or 
Scopus/SciVal for collaborators with established careers and, if they come across your name with incorrect data (i.e., you only have five publications attributed to your name), it may seem like you are only at the beginning of your career. They may move past you in their search for a more experienced collaborator, resulting in a missed opportunity for research that is important to your tenure and promotion.

- It is a great way to keep track of how many citations and other metrics you have and use that to help with promotion and tenure. If publications are not correctly attributed to you, your impact is limited.

- We want to make sure we empathize with their issues on developing an ORCID iD profile. Yes, developing an ORCID profile when someone has a few hundred publications is a bit of a challenge, but it will help faculty because an accurate profile means their respective h-index or citation impact will also be exact and show their true impact in their academic field. Plus, there are also APIs built into ORCID to help make the process easier and will automatically import citations from a variety of indices.

- In the screenshot below from Scopus, you can see the multiple versions of the name John Smith. Without review by the librarian or faculty member, the works can easily be attributed to another university they previously worked for. Additionally, Scopus or WoS may index the publication incorrectly under the wrong Smith (remind them that computer algorithms are not perfect). It is also important to note that errors can occur down on the journal, article, and the author level. A spelling error can occur at any level of publishing and it is important to note that getting the errors corrected takes time and multiple people, but mainly it is the faculty member's responsibility to ensure that their profile is accurate. The library and indices can only do so much before it is up to the researcher.

Figure 2 Example of Different Author Naming Variations

\begin{tabular}{|c|c|c|}
\hline $\begin{array}{l}\text { Smith, Drvid John T. } \\
\text { Smat, D. } \\
\text { Smich, Devid } 1 \\
\text { Smith, D. }\end{array}$ & 495 & Engineering ; Materials Seience ; Bibchemistry, Genetios and Molecular Biologry - \\
\hline \multicolumn{3}{|l|}{ View last title $\checkmark$} \\
\hline $\begin{array}{l}\text { Smith, Thomas john } \\
\text { Smith, Tom } \\
\text { Smith, Thomas } \\
\text { Smith, T. }\end{array}$ & 471 & $\begin{array}{l}\text { Medicine ; Environmental Soience ; Biochemistry. Genetics and Molesular Biology: } \\
\text {-- }\end{array}$ \\
\hline \multicolumn{3}{|l|}{ View last title $\checkmark$} \\
\hline $\begin{array}{l}\text { Walker-Smith, Johr A. } \\
\text { WaLKER-SMiTH, J. A. } \\
\text { Walker Smith, J-A. } \\
\text { WALKER-SMOTH, JOHN }\end{array}$ & 453 & $\begin{array}{l}\text { Medieine ; Immunalogy and Mierobiology; Biochemistry, Geneties and Molecular } \\
\text { Biology, ... }\end{array}$ \\
\hline \multicolumn{3}{|l|}{ View last titie $\checkmark$} \\
\hline $\begin{array}{l}\text { Smith, Matthew john } C \text {. } \\
\text { Smith, Matt } . \\
\text { Smich, Mathew } \\
\text { Smith, M. }\end{array}$ & 376 & Computer Science ; Engineering : Environmental Science; ... \\
\hline \multicolumn{3}{|l|}{ View last title $\checkmark$} \\
\hline $\begin{array}{l}\text { Smith, Jahn R. } \\
\text { Smith, J. R. } \\
\text { Smih, Jahn }\end{array}$ & 256 & Computer Science; Engineering; Physics and Astronamy; ... \\
\hline
\end{tabular}


In spring 2018, KSL began marketing education opportunities to the faculty, encouraging them to register for ORCID iD profiles as well as cleaning up their profiles in both Scopus and WoS. The library also had Elsevier come on two occasions to assist researchers, faculty, staff, and students on how to use Scopus and SciVal for their specific needs. It was very successful and our groups went away with a new understanding of how to use the tools, as well as the benefits of improving their profiles, research, and collaboration. Note that all training is free and, to encourage participation, KSL supplied light refreshments and Elsevier provided a Kindle to one attendee for the two training sessions.

Over the past several months, the RSLs have actively spoken with their departments and KSL has successfully updated almost all of the faculty for the schools directly supported by KSL. Another benefit has been the development of department hierarchies for the schools. These are created in SciVal and have all faculty with at least two publications indexed by Scopus. These hierarchies are then shared with the necessary parties, including department chairs, research deans, and librarians. These individuals are then able to complete analysis on their departments and make adjustments to include prospective candidates in the hiring process or ask any other pertinent questions they might have for their area.

As you can see in the screenshot below, over the past five years, the biomedical engineering department has increased in their scholarly output but decreased in the amount of researchers. This information can help department chairs or deans when looking at candidates to fill one of the open positions in their department or determine which areas of research their faculty are focusing in and help their faculty members look at new collaboration opportunities.

\section{Figure 3 SciVal Department Overview}

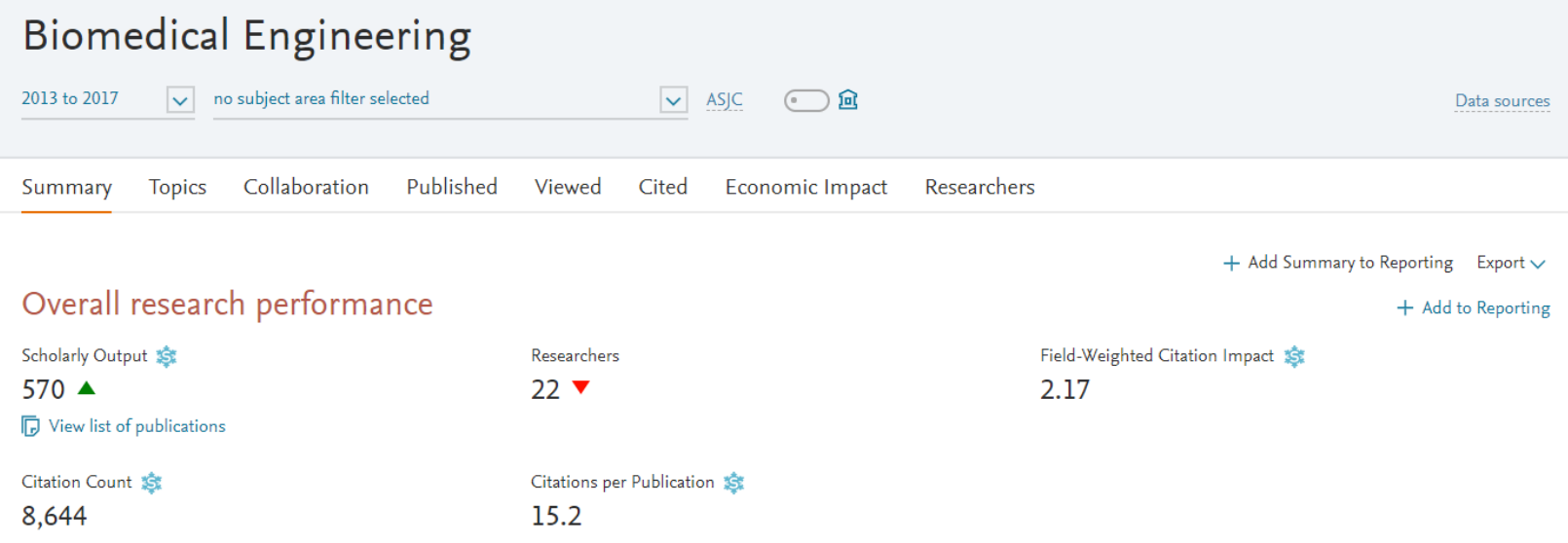

Sharing this information with the departments and schools helped demonstrate the importance of the project, which resulted in more buy-in from the leadership of the departments and schools. This process will be ongoing as the faculty list changes each academic year and requires updates annually.

\section{CURRENT RESULTS:}

The international ranking project began in late 2017 and, after a year of learning as much as possible about international rankings and ranking agencies, making updates to the institution variations, correcting and updating author profiles, scrambling to meet deadlines, and creating new processes and procedures, the Kelvin Smith Library team saw if all of their hard work and effort came to fruition as the results of the new rankings were published in 2018.

When the new rankings for the reporting year started coming out by mid-2018, the assessment librarian was thrilled to see that all of the hard work and late nights paid off. There was concrete proof in the numbers that 
the library contributed to the increase in the university's rankings, especially in the Leiden Rankings, since that is specifically bibliometric.

The chart below shows some success in the first year of CWRU's targeted effort to improve their rankings. It also shows that not all rankings have gone up and some have actually decreased. This is to be expected from time to time if the methodology has changed by the ranking agency or if the university is not performing well in a specific area.

\begin{tabular}{|l|l|l|l|l|l|l|l|l|}
\hline & 2012 & 2013 & 2014 & 2015 & 2016 & 2017 & 2018 & 2019 \\
\hline ARWU & 99 & 99 & 101 & 116 & 111 & 124 & 123 & - \\
\hline QS & 145 & 164 & 175 & 189 & 215 & 202 & 213 & 186 \\
\hline THE & 93 & 104 & 88 & 116 & 133 & 126 & 158 & 132 \\
\hline NTU & 88 & 103 & 116 & 117 & 117 & 116 & 124 & - \\
\hline Leiden & 101 & 101 & 74 & 109 & 133 & 143 & 57 & - \\
\hline $\begin{array}{l}\text { US News } \\
\text { Global } \\
\text { Rankings }\end{array}$ & - & - & - & 137 & 142 & 131 & 146 & 152 \\
\hline
\end{tabular}

One area the university is struggling with in regards to international rankings has been collaboration and connectivity between CWRU authors and international authors. This can cause a ripple effect and impact the rankings. KSL was able to show leadership using InCites and SciVal that the university predominately works more locally and nationally than with international counterparts. The example below shows the SciVal and Scopus data of international collaboration and the total co-authored papers from 2013 through 2017, as indexed by the Scopus dataset.

\begin{tabular}{|l|l|l|}
\hline Region totals & Collaborating Institutions & Co-authored publications \\
\hline Worldwide & 3307 & 14547 \\
\hline Africa & 122 & 420 \\
\hline Asia Pacific & 800 & 2349 \\
\hline Europe & 1166 & 2893 \\
\hline Middle East & 177 & 573 \\
\hline North America & 912 & 12321 \\
\hline South America & 130 & 500 \\
\hline
\end{tabular}

Filter Summary:

Dataset: SciVal

Schema: Scopus 
Time Period: [2013, 2017]

Collaborations with Organizations: [Case Western Reserve University]

\section{AND BEYOND:}

The university created a team of individuals to help improve the rankings, so it was not only KSL's efforts but also the entire university coming together to support this initiative. For 2018, KSL has two representatives that serve on the steering committee and as part of the working group, which includes the university librarian and the assessment librarian. The library is able to share their knowledge and expertise in the process as well as make recommendations. This was especially important during the development of the working group recommendations to the steering committee regarding the strategic recommendations to keep moving the initiative forward. The assessment librarian was able to press that bibliometric work and cleanup cannot be done without WoS and Scopus and the university needs to contribute to the purchasing of the tools to be successful. The university is in the process of finalizing a complete international ranking strategic plan as well as a budget that will include financing at least one of the tools to help support bibliometrics.

For the library initiatives regarding international rankings, KSL is now diving deeper into the data and looking at new areas to support the university. New reporting is now occurring, which includes delving into the research and subject areas to analyze accuracy. Review where faculty are publishing and the impact factor of the journals, including where CWRU's faculty collaborators are located, will help determine if there is a place for international collaboration in the future. Evaluation of the faculty doing work across a range of disciplines can also help determine what the international rankers are looking at and which data points to pay attention to during the next cycle. KSL hopes these projects and others will help administration in the pursuit to improve international rankings in the coming years.

-Copyright 2019 Liz Bernal

\section{Endnotes}

1. "Our History," Case Western Reserve University, http://case.edu/about/history.html.

2. "Think Beyond the Possible: Our Strategic Plan for Case Western Reserve University, 2013-2018," Case Western Reserve University (2013): 2, 5, https://case.edu/provost/sites/case.edu.provost/files/201803/CWRU_2013-18_strategicplan_12-30-13.pdf.

3. "College and university rankings," Wikipedia, accessed October 31, 2018, https://en.wikipedia.org/wiki/College_and_university_rankings.

4. "World University Rankings 2019: methodology," Times Higher Education, THE World Rankings, September 7, 2018, https://www.timeshighereducation.com/world-university-rankings/methodologyworld-university-rankings-2019.

5. World University Rankings 2019.

6. “QS World University Rankings Methodology,” QS World University Rankings, June 6, 2018, https://www.topuniversities.com/qs-world-university-rankings/methodology.

7. "About Academic Ranking of World Universities," Academic Ranking of World Universities, ShanghaiRanking Consultancy, accessed November 6, 2018, http://www.shanghairanking.com/aboutarwu.html.

8. "About Academic Ranking of World Universities."

9. "Sample Selection," NTU Ranking: Performance Ranking of Scientific Papers for World Universities, accessed November 7, 2018, http://nturanking.lis.ntu.edu.tw/methodoloyg/sampleSelection.

10. "Universities," CWTS Leiden Ranking, Centre for Science and Technology Studies, Leiden University, accessed November 7, 2018, http://www.leidenranking.com/information/universities.

11. Robert Morse, Alexis Krivian, and Elizabeth Martin, "How U.S. News Calculated the Best Global Universities Rankings,” U.S. News \& World Report Education, October 29, 2018, https://www.usnews.com/education/best-global-universities/articles/methodology.

12. Morse, Krivian, and Martin, "How U.S. News." 